\title{
DA TOLERÂNCIA AO OUTRO À CELEBRAÇÃO DAS DIFERENÇAS: DIÁLOGO E ALTERIDADE EM DIREITOS HUMANOS E RELIGIÃO
}

O senhor... Mira veja: o mais importante e bonito, do mundo, é isto: que as pessoas não estão sempre iguais, ainda não foram terminadas -. mas que elas vão sempre mudando. Afinam ou desafinam. Verdade maior.

(Guimarães Rosa, em Grande Sertão: Veredas)

Cristiana de Assis Serra*

\section{Introdução}

Nestas eleições de 2014, tivemos a oportunidade de assistir à convergência de três fenômenos. Vimos a intensificação, de um lado, do debate público em torno de diversas pautas pertinentes ao campo dos direitos humanos - tais como a redução das desigualdades socioeconômicas, o racismo e a xenofobia, a redução da maioridade penal e a privatização do sistema prisional, os direitos das mulheres e da população LGBT; e, de outro, do ativismo religioso na esfera pública, por parte de movimentos tradicionalistas que se apropriam de um discurso cristão de caráter notadamente neopentecostal, mas que ultrapassam confissões e denominações específicas (Machado e Piccolo, 2010: 15). Por fim, sobretudo no rastro imediato dos resultados tanto do primeiro quanto do segundo turnos, testemunhamos o acirramento de certa partição binária da sociedade brasileira, que cria narrativas polarizadoras e redutoras da complexidade do campo social ao opor, por exemplo, "ricos" e "pobres", ou "Sul/Sudeste" e "Norte/Nordeste".

Nesse contexto, revela-se mais atual do que nunca a discussão da relação entre os campos dos direitos humanos e religiosos, em termos de dissensões e de possíveis continuidades. Este artigo tem por objetivos esboçar um panorama geral dos direitos humanos, contrapondo-os às narrativas reducionistas e estigmatizantes de indivíduos e grupos minoritários e, partindo do princípio da igualdade na dignidade, tecer pontes com o campo religioso em direção a uma ética da alteridade, que transcenda a mera "tolerância" e efetivamente nos habilite a celebrar a pluralidade.

\section{Igualdade na dignidade: diferença e direitos humanos}

Se, ao longo da História do Ocidente, podemos detectar a percepção da diferença com base nos mais distintos atributos, como corpo, hábitos, posturas e práticas, a constituição da diferença como uma identidade - isto é, como algo que define ontologicamente um dado indivíduo ou coletividade - é algo recente. A concepção iluminista de um "Indivíduo Universal" veio fundar tanto a ideia de "normalidade" quanto seu correlato lógico, a "anormalidade", e

\footnotetext{
*Psicóloga e psicoterapeuta, palestrante e facilitadora de oficinas, grupos de estudos e de meditação.
} 
instituiu assim uma matriz binária que deu origem a outras oposições: superior/inferior, branco/negro, heterossexualidade/homossexualidade, loucura/sanidade, homem/mulher.

A oposição entre normal e anormal, naturalizada no decorrer do século XIX, introduziu uma novidade: a transformação da "diferença" em "desvio" - erigindo-se, a partir daí, uma hierarquia de identidades delimitadas por uma série de táticas e mecanismos que Foucault (2000) denominou de "normalização". As identidades assim forjadas aderem a indivíduos e grupos e passam a defini-los em termos ontológicos. Embora se paute por determinados atributos físicos, psicológicos e comportamentais, contudo, a normalização não se fundamenta em um exame mais apurado das diferenças; ao contrário, constitui-se numa tática de construção de corpos e identidades até então inexistentes.

A arbitrariedade do processo é apontada por Goffman em sua crítica à aplicação do termo "desviante" a indivíduos como se estes "tivessem em comum tantas coisas significativas que (...) poderiam ser considerados como um todo" (1988: 151). Canguilhem, por sua vez, salienta que "a normalidade advirá de sua normatividade" (2000: 113) - isto é, "normal" é aquele dotado de autoridade para definir o "anormal". Portanto, identidade e desvio são correlatos que nada têm de "naturais"; muito pelo contrário, são frutos contingenciais não só de uma construção social e histórica, mas também de um projeto de hegemonia.

Ora, os regimes democráticos, convencionalmente descritos como "governos da maioria", erguem-se sobre dois pilares centrais: o exercício da responsabilidade cívica pela totalidade dos cidadãos e a constituição de um conjunto de princípios e práticas que resguardem os direitos humanos fundamentais de indivíduos e grupos minoritários em face da "vontade da maioria". Se, à primeira vista, esses dois princípios podem parecer contraditórios, é justamente a preservação dos direitos e liberdades individuais e minoritários que assegura a participação destes elementos no jogo democrático, compensando a tendência da maioria a se estruturar e, uma vez consolidada, constituir-se numa autoridade imutável, sufocando as minorias e abafando-Ihes a voz até silenciá-las, conforme adverte Bobbio: "A ameaça que deriva da democracia como forma de governo é (...) a tirania da maioria: o perigo que a democracia corre como progressiva realização do ideal igualitário é o nivelamento, cujo efeito final é o despotismo" (1988: 55, grifo meu).

Com efeito, por si só, "igualdade" é um construto culturalmente localizado que, se não for encarado com olhar crítico, pode nos levar a ignorar práticas e disputas históricas e sociais, explícitas ou dissimuladas, que engendram hierarquias a partir do estabelecimento das posições de normalidade e diferença. Recordamos o alerta de Hannah Arendt:

"Nós não nascemos iguais: nós nos tornamos iguais como membros de uma coletividade em virtude de uma decisão conjunta que garante a todos direitos iguais. A igualdade não é um dado (...), nem resulta de um absoluto transcendente externo à comunidade política. Ela é um construído, elaborado convencionalmente pela ação conjunta dos homens através da organização da comunidade política" (1987: 150). 
Estão em disputa, pois, dois discursos sobre "igualdade". De um lado, aquela que equipara indivíduos e grupos cujas identidades são produzidas nas mais variadas circunstâncias sociais, com o efeito de invisibilizar a desigual distribuição de poder e influência; ao recusar-se a reconhecer a existência de hierarquias sociais e naturalizar categorias construídas em função de determinadas características (reais ou assumidas), contribui para sua perpetuação. De outro, há o discurso que nos reconhece iguais em nossa diferença - no sermos, todos e cada um de nós, únicos e absolutamente originais na complexidade de contingências que nos produzem e no conjunto de traços que nos constituem. Nesse sentido, somos todos semelhantes em nossa (preciosa) singularidade.

$\mathrm{Na}$ medida em que se reconhece nossa igualdade na radical diferença, cria-se um contraponto aos mecanismos de estigmatização de identidades "desviantes". À "violência das mínimas diferenças", para usar a expressão de Burke (2000), vem se confrontar a extensão do status ontológico de "pessoa humana" a categorias até então desumanizadas — ou mesmo demonizadas - e reduzidas à condição de objetos de exclusão. Ao se desnaturalizarem tanto a igualdade que renega nossa singularidade quanto a diferença construída como desvio e estigma, desnaturalizam-se também as categorias e hierarquias socialmente construídas e lançam-se as bases para que grupos que têm sistematicamente vedado ou dificultado o acesso à participação e/ou oportunidade no âmbito coletivo sejam reconstruídos como "minorias" e "grupos vulneráveis", enfim (humanos) sujeitos de direitos humanos.

A própria falta de consenso em relação à definição do termo "minorias", entretanto, denuncia a tensão subjacente a esse processo. A omissão da Declaração de Direitos Humanos da ONU, de 1948, que não incluiu nenhum artigo direcionado especificamente para os direitos das minorias, já revelava a dificuldade explicitada por Capotorti (1979) em termos de "medo e desconfianças" suscitados por iniciativas de prevenção da discriminação e proteção de minorias - entre cujas causas ele cita o perigo representado pela preservação de identidades minoritárias para a unidade e a estabilidade sociais e o risco de que a adoção de medidas especiais de proteção a determinado grupo dê origem a uma "discriminação às avessas". (Tese a que, aliás, costumam recorrer os opositores das assim chamadas "ações afirmativas" - o que é questionável, na medida em que estas se propõem, ao contrário, a assegurar, em caráter temporário, as condições para que segmentos discriminados das populações obtenham igualdade de tratamento com relação à maioria [Pires, 1995:18-19].) Os dois argumentos evocam o fantasma da diferença como uma ameaça à norma e lançam luz sobre as disputas em jogo.

Por outro lado, Regina Pinto, do Departamento de Ciência Política da UFRGS, adverte:

(...) os entusiastas da diferença e de um multiculturalismo ingênuo tendem a ver toda construção de identidade e toda a manutenção da diferença como conquistas. Entretanto, deve-se chamar a atenção para o fato de que um 
considerável número de identidades se constituiu não pelos sujeitos que, por meio delas, foram enunciados, mas pelo seu contrário, pelo dominador. Negros, mulheres, índios, imigrantes, minorias étnicas das mais diversas, todos foram nomeados pelos brancos, homens etc. Características associadas à cor da pele ou ao sexo, à condição social ou à localização espacial, têm-se constituído historicamente como formas de dominação (Pinto apud Freitas, $\mathrm{s} / \mathrm{d})$.

Se a exclusão passa pelo "não-reconhecimento do outro" (ibidem) em sua singularidade e humanidade e guarda íntima conexão com a intolerância - definida por Bobbio, justamente, como a "indevida exclusão do diferente" (1992: 211) —, nem por isso se segue daí que a ela venha se contrapor de forma automática a tolerância, esse outro princípio elementar dos direitos humanos. Pelo contrário: há que problematizar a tolerância, na medida em que esta pode contribuir para manter esse "Outro", já reconhecido em sua humanidade, ainda enquistado na sociedade como uma identidade à parte, em sua diferença indulgentemente "tolerada". Sob esse aspecto, a tolerância não só segrega como objetifica, ao não enxergar no Outro um agente autônomo que seja de fato sujeito de direitos, em vez de mero objeto de proteção - tratamento que se potencializa em certas definições de "grupos vulneráveis", excluídos como as minorias mas, ao contrário destas, "vitimados" também pela ausência de "autodeterminação", "organização" e "solidariedade" que os capacitaria a lutar por seus direitos (cf., por exemplo, Amaral e Trevisan, 2010). A "tolerância", tomada acriticamente, não constitui uma boa solução, prossegue Regina Pinto,

na medida em que tolerar identidades é, ao mesmo tempo, congelá-las e não as integrar. Por outro lado, a inclusão de uma determinada diferença em um dado cenário de forças, em uma dada comunidade, não é um fenômeno simples. A inclusão não é a eliminação da diferença, mas o reconhecimento da diferença (...). Devemos redirecionar a discussão no sentido de buscar formas de redistribuição de poder na sociedade, que tenham como resultado o fim da necessidade de alguns grupos identitários dependerem da tolerância para garantir até mesmo suas vidas (Pinto apud Freitas, s/d).

Daí a Declaração Universal dos Direitos Humanos da ONU, abrir seu preâmbulo consagrando "o reconhecimento da dignidade inerente a todos os membros da família humana e de seus direitos iguais e inalienáveis" como "fundamento da liberdade, da justiça e da paz no mundo" (ONU, s/d). Princípio mais basilar dos direitos humanos, é a partir da noção de dignidade intrínseca a toda pessoa humana que estes devem ser entendidos em sua totalidade; sem ela, o ideal de igualdade e tolerância poderá se converter em mais um mecanismo de reprodução de violências e exclusões.

"A proteção da dignidade da pessoa humana é a finalidade última e a razão de ser de todo o sistema jurídico", assevera Comparato (2001: 38). O postulado da igual dignidade — ou poderíamos chamar de igualdade na dignidade - constitui-se, assim, em fundamento que assegura a vigência dos direitos humanos inclusive para além da organização estatal: 
Esse fundamento, em última instância, só pode ser a consciência ética coletiva, a convicção, longa e largamente estabelecida na comunidade, de que a dignidade da condição humana exige o respeito a certos bens ou valores em qualquer circunstância, ainda que não reconhecidos no ordenamento estatal, ou em documentos normativos internacionais. Ora, essa consciência ética coletiva (...) vem-se expandindo e aprofundando no curso da História. (Comparato, 2001: 37)

A premissa da igualdade na dignidade põe em xeque a tese espúria dos "direitos humanos para humanos direitos", segundo a qual só fariam jus a direitos aqueles indivíduos e grupos que escapassem à desqualificação moral decorrente de uma identidade estigmatizada. Uma vez desnaturalizadas a diferença e a igualdade construídas histórica e socialmente e reconhecida a nossa semelhança na singularidade; uma vez humanizado o Outro diferente de "Nós", de modo a estender o sentido e a referência desse "Nós" a um número cada vez maior de sujeitos (Silva, 2010: 80), a "tolerância" pode então ser transcendida. Assim, não só não incorreremos em condescendência objetificadora do Outro como, ao contrário, uma vez sacramentado seu valor intrínseco, a diferença deixará de constituir uma ameaça para converter-se em elemento da riqueza coletiva que, por isso mesmo, há de ser celebrada.

\section{Da normatização pela Lei à interpelação ética pelo Outro}

Alison (2010) examina o campo religioso buscando compreender a transição da perspectiva das disputas binárias entre normalidade e diferença, inclusão e exclusão, para uma lógica de alteridade - na terminologia usada por esse autor, "fraternidade" — capaz de embasar um compromisso ético sempre renovado com a dignidade da pessoa humana. Ele começa observando que a ordem religiosa estabelecida não só não tem dificuldade com a existência de excluídos como, pelo contrário, depende deles. Assim, configura-se o paradigma segundo o qual a Lei cumpre a finalidade de separar seus seguidores daqueles que não a observam; o objetivo dos primeiros é amalgamar sua unidade coletiva, o que se dá na exata medida em que o elemento contaminador ("eles", os diferentes) é identificado e expulso, segundo o mecanismo de "bode expiatório". Nessa perspectiva, a própria exclusão daquilo que é impuro vai definir o grupo dos eleitos ("nós", os iguais) - em consonância com a tese foucaultiana de que, embora o "anormal" seja, em termos lógicos, derivado do "normal", historicamente a anormalidade antecede a normalidade: primeiro se identifica o "anormal" para depois definir-se o "normal" (Foucault, 2002).

A esse mecanismo Alison contrapõe o paradigma da Criação inacabada, que é oportunidade para manifestar-se a criatividade exuberante de Deus - e que remete à abertura radical ao "Absolutamente Outro", na formulação do filósofo franco-lituano E. Lévinas. É preciso dar espaço para esse Absolutamente Outro (que é necessariamente desconhecido) e acolhê-lo em sua alteridade e integridade. Abordá-lo é algo sempre da ordem de uma aproximação, nunca de um esgotamento, visto que a tradução completa do Outro em algo conhecido 
significaria sua morte - na medida em que "sua radical estranheza [seria] reduzida ao meu total conhecimento de seu sentido, dando vazão ao nosso sonho de estabilidade" (Bernardi, 2003).

Nessa "alteridade radical e absoluta", portanto, deparamo-nos com um enigma que demanda nossa responsabilidade para com esse Outro, de modo a não esvaziá-lo de seu mistério. Foi nesse sentido que, em sua entrevista ao padre Antonio Spadaro, para a revista jesuíta Civiltà Cattolica, o Papa Francisco sublinhou a importância de deixar espaço à dúvida e advertiu contra os riscos da certeza humana e arrogância que nos levam a asseverar que "Deus está aqui":

\begin{abstract}
Encontraremos somente um deus à nossa medida. A atitude correta é a agostiniana: procurar a Deus para $\mathrm{O}$ encontrar e encontrá-l'O para $\mathrm{O}$ procurar sempre. (...) A nossa vida não nos é dada como um libreto de ópera onde está tudo escrito, mas é ir, caminhar, fazer, procurar, ver... Deve-se entrar na aventura da procura do encontro e do deixar-se procurar e deixar-se encontrar por Deus. (Spadaro, 2013)
\end{abstract}

Ora, se considerarmos a tradição cristã ocidental, centrada na Encarnação, "o valor absoluto devido à divindade se estende à humanidade" (Mancuso, 2012): "o sagrado não é mais o templo ou a lei, mas encontra-se nos rostos concretos dos seres humanos"; por isso "o Novo Testamento chega a dizer que não se pode amar a Deus que não se vê se não se ama o próximo que se vê". Daí a interpelação ética desse Absolutamente Outro não se restringir à relação entre o ser humano e Deus, mas materializar-se na prerrogativa radical da dignidade de toda pessoa humana, manifesta não só nas relações interpessoais e coletivas mas também no âmbito subjetivo: ninguém há de objetificar nem ao Outro, nem a si; ninguém profanará a dignidade humana ao reduzir quem quer que seja (nem a si mesmo) a uma identidade previamente construída e já conhecida; ninguém abdicará da radical abertura para o desconhecido nem no outro, nem em si mesmo. Alison (2010: 51-52) alerta para o risco que correm

aqueles que pensam estar completos, aqueles que pensam que a criação está, ao menos no caso deles, finalizada. Por essa razão, acreditam que a bondade se encontra na manutenção da ordem estabelecida (...): a bondade é definida a partir da unidade do grupo, à custa do maligno excluído e por contraste com ele. Os membros moralmente virtuosos do grupo, pensando enxergar, tornaram-se cegos, precisamente ao se agarrarem à ordem que se julgam no dever de defender.

Não se trata, contudo, de inverter posições e identificar-se com as vítimas da exclusão, convertendo-as no novo grupo dos "moralmente justos" e passando a excluir — agora, a partir do referencial de uma nova Lei - quem antes estava incluído entre os "bons". Qualquer oposição entre "nós" e "eles", na medida em que se pauta por uma lógica binária mutuamente 
excludente, levará a santificar um dos lados e demonizar o outro. Com efeito, as divisões polarizadoras em dois opostos inconciliáveis, que classificam o mundo em vítimas e algozes, abusados e abusadores, excluídos e incluídos estão sujeitas, também aqui, ao alerta de Paulo Freire acerca da relação entre oprimidos e opressores: dê-se um pouco de poder ao oprimido, e ele se tornará um opressor. É preciso transcender a lógica da opressão, que só contempla essas duas posições.

Entre um pólo e seu oposto, encontraremos o antídoto no princípio do tertium non datur, o "terceiro" ainda não dado, mediante a introdução da ambivalência, da ambiguidade que teremos de aprender a suportar. Como sugere Alison (2010), quando passamos a colaborar para o estabelecimento de uma nova "virtude" que, por sua vez, também é excludente, surge a oportunidade de nos reconhecermos ao mesmo tempo nas duas posições, como vítimas e algozes. É o momento de "assumirmos nossa participação na hipocrisia farisaica que chama de 'justiça' à exclusão que promove o holocausto do Outro"; só assim se dará "a verdadeira inclusão, aquela que se esvazia da pretensão à virtude ao admitir que é excludente e se justifica ao responsabilizar-se pela inclusão do Outro" (Serra, 2014).

Como não poderia deixar de ser, o processo não transcorre sem dores; se construímos identidades e categorias e nelas nos instalamos, é porque elas introduzem a ordem no mundo e o mantêm sob (aparente) controle. Quanto mais fixas, mais cômodas e seguras as identidades, quando aplicadas tanto aos outros quanto a nós. Reduzimos o Outro ao conhecido porque o desconhecido é perigoso e inquietante, o que vale também para aquilo que nos é estranho em nós. A estabilidade nos reconforta. Como já advertia Dostoiévski em Os Irmãos Karamazov:

Somos assim: sonhamos o voo, mas tememos a altura. Para voar é preciso ter coragem para enfrentar o terror do vazio. Porque só no vazio que o voo acontece. O vazio é o espaço da liberdade, a ausência de certezas. Mas é isso o que tememos: o não ter certezas. Por isso trocamos o voo por gaiolas. As gaiolas são o lugar onde as certezas moram.

Quando a solidariedade baseada na unidade grupal indiferenciada, que se organiza em torno da exclusão do diferente, é abolida, emerge em seu lugar uma nova fraternidade (Alison, 2010), na qual os binarismos certo/errado, bem/mal, recompensa/punição, santo/pecador, incluídos/excluídos são ultrapassados. A aderência ou submissão cegas a categorias coletivas evitam o caminho da responsabilidade individual; a superação desse mecanismo, em contrapartida, funda uma nova ordem ética, capaz de levar em conta a originalidade de cada ser humano e o respeito que lhe é devido - o que não só inviabiliza rótulos niveladores e achatadores, como, sobretudo, realça a originalidade própria de cada indivíduo para além de contextos, molduras e convenções, inclusive os científicos (Serra, 2014).

No entanto, coerentemente, essa nova posição ética não vem esmagar a lógica anterior; pelo contrário, sua consolidação marca também o advento de uma nova disputa entre 
o velho e o novo, a tentação do conhecido e a vertigem do desconhecido, a acomodação e a transcendência, a incorporação do Outro ao Mesmo (já conhecido) e o acolhimento desse Outro em sua irredutível estranheza. O posicionamento unilateral promotor de dominações e apropriações não será simplesmente abolido; a ele virá se contrapor o diálogo ético, engendrando um processo de perene "negociação" - no sentido etimológico resgatado por Derrida de "não-descanso" (Bernardi, 2003) - com esse Outro que nos interpela, demanda nossa atenção e responsabilidade e nos mantém em perpétuo movimento.

Por um lado, essa ética centrada no Outro abre espaço para sua plena dignidade, enquanto radicalmente diferente do Eu; por outro, passa a conferir sentido para o próprio Eu, na medida em que inaugura um paradigma de hospitalidade absoluta, no qual a face enigmática do Outro é acolhida sem que se tente reduzi-lo ao Mesmo, sem submetê-lo a uma domesticação tal que seu mistério se transforme no conhecido que o Eu é capaz de aceitar e suportar (Bernardi, 2003). O projeto hegemônico de estabilidade e ampliação do Mesmo é suplantado pela abertura para o voo no desconhecido proporcionado pelo Outro, lançando-se ao encontro da diferença "em sua diferencialidade mesma": o Outro como Outro, não mais como mero reflexo ou função do Mesmo (Serra, 2014).

\section{Conclusão: por uma ética da alteridade}

A novidade do cristianismo reside na desvinculação dos valores religiosos do reino da violência, da reivindicação, da vingança, do antagonismo; na preconização da gratuidade e da responsabilidade ética do Eu pelo Outro, em que a existência de um não implica na exclusão, vitimização nem separação do Outro, como sublinha Libânio (apud Alison, 2010: 22). Em termos de elaboração teológica, trata-se, evidentemente, de um processo longo e incoerente, e não há como ignorar a violência que permeia a história cristã. Não obstante, como evidencia o desenvolvimento do próprio discurso dos direitos humanos, vem se consolidando na cultura ocidental - de maneira irreversível, aponta Mancuso (2012) - "a aquisição de que a única coisa sagrada é a vida livre dos seres humanos"; cada vez mais fica claro "que a dimensão mais alta do sagrado é o ser humano vivo à imagem de Deus".

"O cristianismo é jovem, tem apenas dois mil anos - e talvez só agora, cada vez mais livre dos interesses do poder, graças à secularização, esteja começando a lidar seriamente com as diversidades do mundo", especula Mancuso (ibidem). Com efeito, presenciamos hoje "uma profunda transformação do conceito de sagrado, que não pretende ter nada a ver com a concepção primitiva e machista do culto da força e da arbitrariedade, incluindo o Deus do teísmo e da onipotência de algumas páginas bíblicas".

O que cada vez mais se torna sagrada para a consciência é a lealdade nas relações, a harmonia em perene busca e construção, o rosto humano sob qualquer aspecto - em uma transformação profunda do próprio conceito de religião. No entender de Mancuso, consolidam- 
se assim as premissas para que se cumpra a revolução teológica do Cristo: a passagem do teísmo ao panenteísmo.

À diferença do "panteísmo", segundo o qual tudo é Deus, Deus é tudo e não comporta nenhuma diferença, diluindo todo Eu no Outro, o "panenteísmo" significa que Deus está em tudo e tudo está em Deus, numa relação dinâmica de alteridade. "Deus e mundo são diferentes. Mas não estão separados ou fechados. Estão abertos um ao outro. Se são diferentes, é para possibilitar o encontro e a mútua comunhão" (Boff, 2012).

Não por acaso, temos visto um Papa preconizar, insistentemente, o valor do diálogo, da "cultura do encontro", do deixar-se surpreender pelo Outro e de uma ética de serviço a esse Outro, de uma Igreja "de portas abertas", pois, com efeito, o antídoto à violência é a hospitalidade. Só portas radicalmente abertas podem assegurar que não se profane nem o Outro, nem o Eu, em sua inalienável — e sagrada — dignidade. Só uma ética da alteridade nos permitirá, mais que tolerar, efetivamente celebrar a diferença e a diversidade como expressão mesma da inapreensível magnitude de Deus.

(Este artigo é uma elaboração de temas abordados informalmente na palestra de mesmo título proferida no dia 19 de setembro de 2014, no contexto da semana da CRE da PUC-Rio, que teve por tema "Religiões e Direitos Humanos: 'a Paz é fruto da Justiça' (Is 32,17)". As questões aqui discutidas são tratadas por um viés prático, através de situações do dia a dia, em uma série de postagens em meu blog, que podem ser acessadas no endereço http://bit.ly/104BBZa.)

\section{Questões para reflexão}

1. O jornalista Moisés Sbardelotto, no artigo "A comunicação do Papa Francisco e a "cultura do encontro': das palavras aos gestos", reproduzido no site do Instituto Humanitas Unisinos em novembro de 2013 (http://bit.ly/104F6Pj), comenta a carta aberta endereçada pelo Papa Francisco ao diretor-fundador do jornal italiano La Repubblica, o jornalista Eugenio Scalfari:

(...) retomando o Concílio Vaticano II, Francisco afirmou que "chegou agora o tempo (...) de um diálogo aberto e sem preconceitos que reabra as portas para um sério e fecundo encontro" entre a Igreja e a cultura contemporânea. Para poder estabelecer tal diálogo, segundo o papa, é preciso reconhecer a verdade não a partir de sua dualidade absoluta/relativa, mas sim como relacional: para a fé cristã, a verdade é "o amor de Deus por nós em Jesus Cristo. Portanto, a verdade é uma relação!", afirmou Só a partir desse reconhecimento é possível estabelecer um "diálogo sereno e construtivo" com a cultura, sem aprioris que o engessem e o transformem em monólogo. Assim, a alteridade, a diversidade e as verdades do outro ajudam a descobrir a identidade, a unidade e a verdade do nosso próprio ser.

Discuta os temas do diálogo e do encontro, tal como sintetizados por Sbardelotto em sua análise, em relação ao tema da alteridade e da celebração das diferenças examinado neste artigo. 
2. O jornalista Leonardo Sakamoto, no artigo "Precisamos queimar cuecas em praça pública", publicado em seu blog (http://bit.ly/104GWQq) no Dia Internacional da Mulher de 2012, observa que

O homem é programado, desde pequeno, para que seja agressivo. Raramente a ele é dado o direito que considere normal oferecer carinho e afeto para outro amigo em público. Manifestar seus sentimentos é coisa de mina. Ou, pior, é coisa de bicha. De quem está fora do seu papel. E vamos causando outros danos no caminho: há mulheres que, para serem aceitas nesse mundo de homens, buscam nos copiar no que temos de pior.

Comente a relação binária entre as identidades homem/mulher em nossa sociedade, considerando os tipos de violência que gera e apontando possibilidades para sua superação.

3. A cientista social Rosana Pinheiro-Machado, no artigo "Etnografia do 'Rolezinho"”, publicado em janeiro de 2014 no site da revista Carta Capital (http://bit.ly/104HPs7), examina o fenômeno dos "rolezinhos" nos shoppings em termos da segregação de classes e da desigualdade social:

Estou acompanhando os "rolezinhos" e sinto certo prazer em ver aquela apropriação. Mas entre apropriação e resistência há um abismo significativo. Adorar os símbolos de poder - no caso, as marcas - dificilmente remete à ideia de resistência que tanta gente procura encontrar nesse ato. O tema é complexo, não apenas porque desvela a segregação de classe brasileira, mas porque descortina a tensão da desigualdade entre países desenvolvidos e em desenvolvimento, entre o Norte e o Sul. E enquanto esses símbolos globais forem venerados entre os mais fracos, a liberdade nunca será plena e a pior das dependências será eterna: a ideológica.

A partir da leitura desse texto e em diálogo com este artigo, elabore uma reflexão a respeito das possibilidades e limites da apropriação de símbolos e espaços simbólicos para a superação da violência.

\section{Referências bibliográficas}

ALISON, J. Fé Além do Ressentimento. São Paulo: É Realizações, 2010.

AMARAL, S.T. e TREVISAN, A.F. Diferenciação entre minorias e grupos vulneráveis. In: ETIC Encontro de Iniciação Científica, Vol. 6, No 6 (2010). Disponível em http://intertemas.unitoledo.br/revista/index.php/ETIC/article/view/2319/1814. Acessado em 31/10/2014.

ARENDT, H. A condição humana. São Paulo: Universitária, 1987.

BERNARDI, C. Individoação: do Eu para o Outro, Eticamente. III Congresso Latino-Americano de Psicologia Junguiana, maio de 2003, Salvador (BA). Disponível em http://www.rubedo.psc.br/artigosb/jgetiind.htm. Acessado em 01/11/2014.

BOBBIO, N. A era dos direitos. Rio de Janeiro: Campus, 1992. . Liberalismo e Democracia. São Paulo: Brasiliense, 1988. 
BOFF, L. Panteísmo versus Panenteísmo. In: Instituto Humanitas Unisinos, 16/04/2012. Disponível em http://www.ihu.unisinos.br/noticias/508499-panteismoversuspanenteismo. Acessado em 01/11/2014.

BURKE, P. A violência das mínimas diferenças. In: Jornal Folha de São Paulo, Caderno MAIS!, 21/05/2000. Disponível em http://www1.folha.uol.com.br/fsp/mais/fs2105200010.htm. Acessado em 31/10/2014.

CANGUILHEM, G. O Normal e o Patológico. Rio de Janeiro: Forense Universitária, 2000.

CAPOTORTI, F. Study on the Rights of Persons Belonging to Ethnic, Religious and Linguistic Minorities. U.N. Doc E/CN.4/Sub.2/384/Rev.1, U.N. Sales No. E.78. XIV.1, 1979.

COMPARATO, F. K.. A afirmação histórica dos direitos humanos. São Paulo: Saraiva, 2001.

FOUCAULT, M. Os Anormais. São Paulo: Martins Fontes, 2002. Vigiar e punir. Petrópolis (RJ): Vozes, 2000.

FREITAS, Fábio. Democracia, igualdade, diferença e tolerância. In: Enciclopédia Digital Direitos

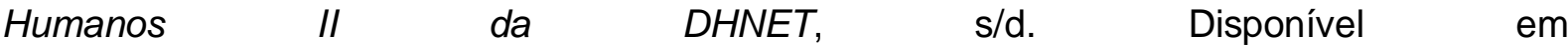
www.dhnet.org.br/direitos/militantes/fabiofreitas/texto45.htm. Acessado em 01/11/2014.

GOFFMAN, E. Estigma: Notas sobre a Manipulação da Identidade Deteriorada. Rio de Janeiro: LTC, 1988.

MACHADO, M.D.C. e PICCOLO, F.D. (orgs.) Religiões e homossexualidades. Rio de Janeiro: FGV, 2010.

MANCUSO, V. O que resta do sagrado: o cristianismo, a ética e o Ocidente. In: Instituto Humanitas Unisinos, 18/11/2012. Disponível em http://www.ihu.unisinos.br/noticias/515605o-que-resta-do-sagrado-o-cristianismo-a-etica-e-o-ocidente-artigo-de-vito-mancuso. Acessado em 01/11/2014.

ONU. Declaração Universal dos Direitos Humanos, s/d. Disponível em http://www.onu.org.br/img/2014/09/DUDH.pdf. Acessado em 30/10/2014.

PIRES, M.J.M. A discriminação positiva no direito internacional e europeu dos direitos do homem. Documentação e Direito Comparado, Lisboa, n. 63-64, 1995.

SERRA, C.A. De Sodoma à Samaria: Cristianismo, Homofobia e Alteridade no Brasil. In: BOECHAT, W. (org.) A Alma Brasileira: Luzes e Sombra. Petrópolis (RJ): Vozes, 2014.

SILVA, S.G. Direitos humanos: entre o princípio de igualdade e a tolerância. In: Revista Praia Vermelha, Rio de Janeiro, v. 19 nำ 1, jan-jun 2010, p. 79-94.

SPADARO, A. Íntegra da entrevista de Francisco à 'Civiltà Cattolica'. 19/09/2013. Disponível em http://fratresinunum.com/2013/09/19/integra-da-entrevista-de-francisco-a-civilta-cattolica/. Acessado em 01/11/2014 